NASA Technical Memorandum 106826 AIAA-95-0538

\title{
Ice Accretion with Varying Surface Tension
}

\author{
Alan J. Bilanin \\ Continuum Dynamics, Inc. \\ Princeton, New Jersey \\ for \\ NYMA, Inc. \\ Engineering Services Division \\ Brook Park, Ohio \\ David N. Anderson \\ Lewis Research Center \\ Cleveland, Ohio
}

Prepared for the

33rd Aerospace Sciences Meeting and Exhibit

sponsored by the American Institute of Aeronautics and Astronautics

Reno, Nevada, January 9-12, 1995

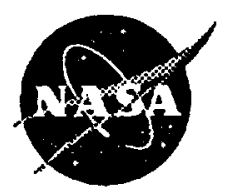

(NASA-TM-106820) ICE ACCRETION
WITH VARYING SURFACE TENSION
(NASA. LEWIS RESEJTCh CENTER) 13 p

N95-19285

Unclas

National Aeronautics and 



\title{
Ice Accretion with Varying Surface Tenaion
}

\author{
Alan J. Bilanin \\ Continuum Dynamics, Inc. \\ and \\ David N. Anderson \\ NASA Lewis Research Center \\ Cleveland, $\mathrm{OH}$
}

\begin{abstract}
During an icing encounter of an aircraft in flight, super-cooled water droplets impinging on an airfoil may splash before freezing. This paper reports tests performod to determine if this effect is significant and uses the results to develop an improved scaling method for use in icing test facilities. Simple laboratory tests showed that drops splash on impact at the Reynolds and Weber numbers typical of icing encounters. Further confirmation of droplet splash came from icing tests performed in the NASA Lewis Icing Research Tunnel (IRT) with a surfactant added to the spray water to rectuce the surface tension. The resulting ice shapes were significantly different from those formed when no surfactant was added to the water. These results suggested that the droplet Weber number must be kept constant to property scale icing test conditions. Finally, the paper presents a Weber-number-based scaling method and reports results from scaling tests in the IRT in which model size was reduced up to a factor of 3 . Scale and reference ice shapes are shown which confirm the effectiveness of this new scaling method.
\end{abstract}

\section{Nomenclature}

$A_{c} \quad$ Accumulation parameter, dimensionless

$b$ Relative heat factor, dimensionless

c Characteristic model length, $\mathrm{cm}$

$c_{p} \quad$ Specific heat, cal $/ \mathrm{gm} \mathrm{K}$

$h_{c} \quad$ Convective film heat-transfer coefficient, $\mathrm{cal} / \mathrm{sec} \mathrm{m}^{2} \mathrm{~K}$

$k$ Thermal conductivity, cal/sec $m \mathrm{~K}$

LWC Liquid-water content, $\mathrm{g} / \mathrm{m}^{3}$

$M \quad$ Mach number, dimensionless

$n \quad$ Freezing fraction, dimensionless

$\mathrm{Nu} \quad$ Nusselt number, dimensionless

$p \quad$ Ambient static pressure, $\mathrm{nt} / \mathrm{m}^{2}$

$p_{w} \quad$ vapor pressure of water, $\mathrm{nt} / \mathrm{m}^{2}$

$R_{a} \quad$ Gas constant for air, $287.0 \mathrm{nt} \mathrm{m} / \mathrm{kg} \mathrm{K}$

$\mathrm{Re} \quad$ Reynolds number, dimensionless

$t \quad$ Ambient static temperature, ${ }^{\circ} \mathrm{C}$

$T \quad$ Ambient static temperature, $\mathrm{K}$

$U$ Droplet velocity, $\mathrm{m} / \mathrm{s}$

$V \quad$ Airspeed, $\mathrm{m} / \mathrm{s}$

We Weber number, dimensionless

$\delta \quad$ Droplet median volume diameter, $\mu \mathrm{m}$

$\Delta \quad$ Film thickness or ice thickness, m

b Droplet-energy transfer term in energy equation, $K$ $\theta \quad$ Air-energy transfer term in energy equation, $K$

1 Latent heat of freezing, $\mathrm{cal} / \mathrm{gm}$

$\Lambda_{v} \quad$ Latent heat of vaporization, cal/gm

$\rho$ Density, dyne $/ \mathrm{cm}^{3}$

H Viscosity, gm/cm s

$\sigma_{w / a}$ Surface tension of water against air, dyne/cm

$\tau$ lcing time, $\min$

Subscripts:

$\begin{array}{ll}a & \text { Air } \\ \delta & \text { Based on droplet size } \\ f & \text { freezing point } \\ i & \text { Ice } \\ m & \text { Measured } \\ R & \text { Reference size and conditions } \\ s u r f & \text { Surface } \\ S & \text { Scale size and conditions } \\ \text { tot } & \text { Total } \\ T & \text { Theoretical } \\ w & \text { Water }\end{array}$

Introduction

Wind tumel icing tests of subscale aerodynamic components bave been undertaken for decades. Yet, scaling laws which relate tunnel data to predict what would be anticipated during operation of the component in the atmosphere have yet to be agreed upon. This is evident from reviews of scaling laws by Bilanin ${ }^{1}$ in 1988 and Anderson $^{2}$ in 1994 . There exist about half a dozen methodologies which have competed over the years for international acceptance, but in spite of years of validation testing, to date no methodology has shown a clear adventage. One reason is that until quite recently, the ability of a wind tumel test engineer to set icing test conditions such as droplet size and liquid-water content, has been hindered with instrumentation and calibration shortcomings. The second, and probably more important, reason is that almost without exception previous scaling methodologies have ignored water droplet impact and film dynamics in the scaling analysis. This observation was brought to the attention of the icing community in $1988^{1}$. This paper reports on the first attempt to provide experimental evidence that droplet impact and water film dynamics cannot be neglected in the derivation of scaling laws, especially under icing conditions where low freezing fractions are anticipated. The results presented bere are significant not just for scaling but they also suggest that ice accretion codes need to implement droplet impact and liquid-film dynamic models to 
improve the accuracy of predictions. Discrepancies between predicted and measured ice shapes are often blamed on inaccuracies in modeling the convective heat transfer coefficient. We suspect that some of this discrepancy could be explained by considering droplet-surface interactions.

Evidence that all is not well with past scaling methodologies was presented in reference 1 where it was argued that if both the accumulation factor, $A_{c}$ and the freezing fraction, $n$, were sccurately known at each point along an aerodynamic component, the prediction of ice accretion and a comparison between this prediction and test data must agree favorably. It was then shown using test data along with the scaling methodology in the SMMCE scaling code ${ }^{3}$ that seriously misunderstood discrepancies exist. The SIMICE code computes the freezing fraction according to the Messinger analysis ${ }^{4}$. Figure 1 is taken from reference 1 and shows the measured and preticted ice thickness at the stagnation point for two lests having predicted freezing fractions, $n_{T}$, of .15 and .5 . The stagnation-point ice thickness is exactly proportional to $A_{c} n$, and the predictions in figure 1 were based on this. The actual measured freezing fractions, $n_{m}$, were .35 and .6 , respectively. Ice thicknesses for the lower freezing fraction were greater than predicted by a factor of 2.3 . Thus, either the freezing fraction computation or the estimate of accumulation parameter were in error.

The suspicion that something may not be correct with the methodology for computation of the collection factor is motivated by the observation of raindrops impacting a shallow puddle. The schematic of this collision is shown in figure 2. Here, for the sake of argument and to good approximation during the interaction of the droplet with the film, we will neglect the shear forces of the air on the droplet. Then the droplet film dynamics are controlled by only three nondimensional parameters:

$\begin{array}{ll}\Delta \delta & \text { film thickness/droplet diameter } \\ \rho_{w} U \delta / \mu_{w} & \text { Reynolds number } \\ \rho_{w} U^{2} \delta / \sigma_{w / a} & \text { Weber number }\end{array}$

Also, we know from observations that rain drops splash upon impacting a water layer. In Table I, we have computed and tabulated the typical order of magnitude values of these three nondimensional parameters for both rain and icing conditions. Quite surprising is the result that in general the values of the Reynolds and Weber numbers for rain are typical of the values during icing. Hence, one can study the impact of $1-\mathrm{mm}$ raindrops moving at $10 \mathrm{~m} / \mathrm{s}$ impacting a $1-\mathrm{mm}$ film instead of studying the impact of a 20- $\mu \mathrm{m}$ droplet impacting a film at $500 \mathrm{kts}$.

This paper presents the results of simple experiments to confirm the importance of doplet splashing at $R e$ and We representative of icing encounters. Icing tests in the NASA Lewis Icing Research Tumel are described in which the surface tension of the spray was altered by the addition of a surfactant. Finally, a practical scaling method is described and tested in which the droplet We is maintained the same between scale and reference conditions.

\section{Droplet Splashing Teats}

The above discussion mentioned the use of slow-moving large water droplets impacting a water film to determine if film dynamics and splashing can be neglected in the development of scaling laws and in computer models of the ice sccretion. In this section, we report on simple tests which have been conducted to examine droplet impact dynamics relevant to icing.

Figure 3 is a sketch of the droplet-impact rig used during testing. A burette is mounted at distance $h(h<5 \mathrm{~m})$ above a small dish sitting on a milligram scale. By slowly allowing the water to drop from the burette and counting the number of drops produced per milliliter, ane con easily compute a typical droplet diameter. From previous wark involving spray dispersion in aircraft vortex wakes for water droplets released from rest into still air, the velocity of the droplet as a function of release height, $h$, is known. In the tests reported here, the droplet diameter was $4.7 \mathrm{~mm}$ and the impact velocity from a release height of 1 and $4.7 \mathrm{~m}$ was 4.2 and $8.1 \mathrm{~m} / \mathrm{s}$, respectively.

The results are plotted on figure 4 where drops impact a film which is $1 / 3,2 / 3,3 / 4$ and $4 / 3$ of the impecting drop diameter. Plotted on the vertical axis is the percent of mass gained after the impact. For example, if the incoming drop's mass is completely added to the film, the percent mass gain would be $100 \%$. Even at the lower impact velocities of $4.2 \mathrm{~m} / \mathrm{s}$, on the order of $25 \%$ of the incoming mass is splashed away. At the highest impact velocities, a more surprising result is obtained in that it is possible to lose mass of liquid from the film. A mass loss of $100 \%$ implies that for every incoming droplet, two droplets are splashed away. Note that the results are strongly dependent on the film-thickness-to-dropdiameter ratio, and film thicknesses which are less than the diameter of the incoming drop seem to experience the most mass jection from the film. Note that each test condition was repeated a minimum of three times, and the repeatability appears to be quite high.

Figure 4 gives the Weber and Reynolds numbers for the tests conducted. These can be compared to Table I where it can be seen that these values are in fact typical of those anticipated during icing. The above results therefore strongly suggest that droplet splashing and droplet impact dynamics with a liquid film may be important in the development of scaling laws and also must be modeled if ice accretion computer codes are to make physically realistic predictions of ice accretion.

\section{Icing Tunnel Experimentt}

If troplet splashing has an effect on the ice-accretion process, then varying the surface tension of the spray water will change the ice shape. Two tests were performed in the NASA Lewis Icing Reseanch Tumnel (IRT) to evaluate the effect of surface tension on ice shape. For the first test, Liqui-Nox, a commercial cleaning solution, was added to the spray-bar water supply so that the entire IRT spray had reduced surface tension. For the second test, Kodak Photo-Flo 600 was added to the spray of a single nozale directed at the center of the test section while the IRT spray bars maintained 
their normal spray of demineralized water.

The results of these tests led to the development of a scaling method based on the requirement that the Weber number, $W e$, be matched between scale and reference tests. Additional tests were performed in the IRT to evaluate this method. The surfactantaddition tests, the constant-We scaling method and the scaling tests and results will be described in this section.

NASA Lewis lcing Research Tumel. The IRT is shown in figure 5 . It has been described in reference 6 . The IRT has a test section width of $2.74 \mathrm{~m}(9 \mathrm{ft})$ and a height of $1.83 \mathrm{~m}(6 \mathrm{ft})$ It is capable of operation at test-section airspeeds up to $160 \mathrm{~m} / \mathrm{s}$ (350 mph) A refrigeration system permits accurate control of the test-section temperature from 230 to $278 \mathrm{~K}\left(-40\right.$ to $40^{\circ} \mathrm{F}$.) A water-spray system 7 with 8 spray bars provides the ability to control test-section liquid-water content from .2 to $3 \mathrm{~g} / \mathrm{m} 3$ and droplet median volume diameters from 15 to $40 \mu \mathrm{m}$

Two sets of spray nozzles, known as the mod-1 and standard nozzles, are used in the IRT to provide different ranges of liquid-water content and droplet size 7 . For these tests, only the mod-1 nozzles were used.

For tests using a single nozzle to add surfactant, a mod-1 nozzle was mounted on the spray-bar support and aimed so that its spray struck the model at the centerline of the test section. This nozzle was supplied with air from the spray-bar manifold while it received water from a tank independent of the spray-bar supply. The singlenoezle water pressure was controlled to the same value as the water pressure for the spray bars. When the single nozzle was used, surfactant was added to its water supply while the main spray system used demineralized water with no additive. It was found by ice shape comparisons when demineralized water with no surfactant was sprayed from the single nozale, that of the total water reaching the center of the model, about $10 \%$ came from the single noenle and the rest from the main spray bars. Consequently, for all the single-nozzle tests the spray-bar pressures were set for a liquid-water content of $90 \%$ the desired value.

The tests of the constant-We scaling method were performed without surfactant.

Test Hardware. Ice accretion was measured on hollow circular ahuminum cylinders. Each cylinder was mounted vertically in the center of the test section. Cylinders with 15.2-, 7.6-, 5.1- and $2.5-\mathrm{cm}(6-, 3-, 2-$ and 1-in) diameters were used. Figure 6 shows how each cylinder was positioned in the IRT test section. A retractable shield was positioned in front of the cylinder to protect it from spray during the spray-bar start-up period when the water and air pressures were stabilizing. The shield could be retracted rapidly into the tunnel ceiling by remote operation of a hydraulic actuator.

Test Procedure. Tests were performed by first establishing the desired velocity and temperature. Water spray conditions were then selected, and when tunnel conditions had stabilized, the water spray was initiated. The shroud protecting the test cylinder from the spray was lifted when the spray conditions had stabilized, and the spray timer was started at this time. When the prescribed spray period was completed, the spray was shut off and the tumnel brought to idle to permit persomel entry into the test section. The ice shape was recorded by first melting a thin slice through the ice nomal to the cylinder axis. The shape was traced onto a cardboard template; these shapes were later digitized and recorded on a computer disk. After the ice shape was recorded, the model was cleaned and the procecture repeated for the next spray condition.

\section{Results: Surface-Tension Experiments}

Surface Tension Measurements The surface tension of the demineralized IRT water, two dilutions of water:Liqui-Nox mixtures, two dilutions of water:Photo-Flo 200 mixtures and a water:Photo-Flo 600 mixture was measured. Photo-Flo 600 is a more concentrated form of Photo-Flo 200 so that a 600:1 mix of water to Photo-Flo 600 is equivalent to a $200: 1 \mathrm{mix}$ of water to Photo-Flo 200. Measurements were made on three occasions using an epparatus which employed the ring-detachment method, and the results are given in Table I. The published value ${ }^{8}$ of surface tension for water at $20^{\circ} \mathrm{C}$ is $73 \mathrm{dyne} / \mathrm{cm}$. When there are impurities present, however, the surface tension will be less than this. It is not surprising, then, that the surface tension of water was found to be lower than the published value. The addition of surfactant in the form of Liqui-Nox or either of the Photo-Flo concentrations rectuced the surface tension of the IRT water to about half its untreated value. Furthermore, increasing the dilution of the water:surfactant mixture had virtually no effect on the surface tension.

Effect of Reduced Surface Tension on Ice Shape Initial tests with surfactant addition were made with Liqui-Nox added to the entire spray bar water supply. At the conclusion of these tests, it was necessary to flush the entire spray bar system thoroughly to remove any traces of the surfactant for subsequent icing tests with demineralized water. To avoid the inconvenience of this purging procecture, a single spray nozzle with its own water supply was mounted on the spray-bar array in a such a position that its spray would strike the model at the center of the test section. Thus, the single noezle could be operated with surfactant-treated water while the full spray-bar system operated with untreated demineralized water. Because ice shapes were only measured at the center of the model for this study, this arrangement would be effective if it produced the same ice shapes as resulted from adding surfactant to the full spray-bar system.

To test the single-nozzle system, Kodak Photo-Flo 600 in a mixture of 600:1 water:Photo-Flo was used in the single-nozzle water supply. A comparison of centerline ice shapes using the singlenoezle and full-spray-bar surfactant addition methods is shown in figure 7. The solid line represents the shape resulting from adding Liqui-Nox to the spray-bar water supply. The dotted line indicates the ice shape accreted when the single nozale operated with the water:Photo-Flo mixture. The shapes of the ice formed by either method of delivering surfactant agree within the normal repeatability of the tumnel. This result verifies that the simpler single-nozzle method of surfactant addition gives results at the centerline which are equivalent to the less-desirable method of 
As noted above, the single nozale contributed only about $10 \%$ of the total water reaching the model centerline. Thus, most of the incoming drops would not have the reduced surface tension when the single noezle was used to add surfactant. Apparently, then, the impacting droplet surface tension was of less importance to the physics of the process than the surface tension of the unfrozen water on the surface of the model. Because dilution has little effect on surface tension, once the treated droplets mixed with water on the surface, the surface tension of the surface mixture would be expected to be about the same for either method of adding surfactant.

To test the effect of surfactant on ice shape, conditions were run which had previously been used with unactulterated demineralized water. The results are shown in figure 8 . The solid line gives the shape at the centerline produced with demineralized water, and the dotted line represents the shape when surfactant was added to the spray. In figure 8(a) results are given for tests in which 1 part of Liqui-Nox cleaner was added to 400 parts (by volume) of demineralized water. The addition of surfactant totally changed the shape of the horns and reduced the horn angle.

Results for the single-nozale surfactant-addition tests are given in figure 8(b). Again, surfactant addition had a dramatic effect on the shape of the ice. Although droplet splashing has been shown in the bench-top experiments described previously in this paper to be significant, an additional effect of the surfactant on ice shape may also result from a reduction in droplet size. When the surface tension is halved, the droplet size can be expected to decrease by about $25 \% 9$. For the single-nozzle tests only about $10 \%$ of the droplets have recuced surface tension, however, so the median volume diameter of the total spray should be close to that for water without surfactant. The freezing temperature of the water:Photo-Flo mixture was tested and found to be the same as water. Although the mixture latent heat was not measured for this study, it should be the same as water because of the extremely small amount of surfactant used. Thus, the primary reason for the differences in ice shape with and without surfactant is apparently the change in the surface tension of unfrozen water on the surface of the model. This observation reinforces the conclusion of the droplet-splashing tests that droplet-surface interaction plays a significant role in the ice-accretion process.

\section{Implications for Scaling}

The strong effect of droplet-surface interaction demonstrated by both the splashing tests and the icing-tumnel tests suggests that the Weber number needs to be considered in developing scaling methods. Rigorous scaling would require that the Reynolds and Weber numbers be matched between scale and reference conditions ${ }^{1}$. To do this it is necessary that, approximately,

$$
V_{S}=V_{R} \frac{c_{R}}{c_{S}}
$$

$$
\sigma_{s}=\sigma_{R} \frac{c_{R}}{c_{s}}
$$

Thus, for a half-size model, for example, both the airspeed and the surface tension of the spray need to be roughly doubled over their desired reference values. While it is relatively easy to reduce surface tension by adding surfactant to the spray water, increasing the surface tension of the spray to satisfy equation (2) does not appear to be practical. Furthermore, the airspeeds required by equation (1) for small-scale models will generally produce unacceptably high Mach numbers. It seems, then, that this approach to scaling is likely to be unusable for most scaling situations. However, a practical scaling method can be developed by relaxing the need to match $R e$ between scale and reference situations. This is a reasonable simplification, for the Re should have little effect on the flowfield, provided the flow becomes uurbulent over some part of the body. With glaze ice shapes, the point of separation and transition are determined by the ice shape rather than by the $R e$. Consequently, a scaling method was developed which is based on maintaining the same We for both scale and reference conditions and ignoring the Re. This method is discussed in the following sections.

Constant-Weber-Number Scaling. The method is outlined here. Results from preliminary tests to verify the method in the IRT are described in the next section.

Unlike other published scaling methods ${ }^{2}$, this method permits only the choice of scale model size, $c_{s}$. The reference model size, $c_{R}$ and all reference conditions are, of course, known. The following four equations are first solved simultaneously to give the scale airspeed, $V_{S}$ scale static temperature, $T_{S}$ scale static pressure, $p_{S}$ and scale drop size, $\delta_{S}$ :

$$
\begin{gathered}
V_{S}=V_{R}\left(\frac{8_{R}}{8_{S}}\right)^{\frac{1}{2}} \\
T_{S}=T_{R}+\frac{V_{R}^{2}}{2 c_{\text {pingor }}^{2}}-\frac{V_{S}^{2}}{2 c_{p, w a d r}}
\end{gathered}
$$

$$
P_{s}=\frac{P_{\text {tots }}}{1+\frac{V_{s}}{2 R_{\varepsilon} T_{s}}}
$$

$$
\delta_{S}=8_{R}\left(\frac{c_{S}}{c_{R}}\right)^{.02}\left(\frac{P_{S}}{P_{R}}\right)^{.24}\left(\frac{V_{S}}{V_{R}}\right)^{-38}
$$


Equation (3) results from matching the scale and reference We, and equation (4) is obtained by matching droplet energy transfer terms (see equation (9), below) in the Messinger energy balance ${ }^{4}$ at the model surface. There is no fundamental necessity that the droplet energy terms be matched; however, an equation is needed to solve for the static temperature, and equation (4) is convenient. Equation (5) simply relates the static pressure in the tumnel to the known ambient pressure (tumnel total pressure) and equation (6) results from matching the droplet trajectories.

The froezing fraction, $n$, was defined by Messinger ${ }^{4}$ as the fraction of impinging water which freezes in the impingement zone. The scale $L W C$ is found by equating the scale and reference freezing fraction. From the Messinger energy equation, the freezing fraction is

$$
n=\frac{c_{p, w}}{\Lambda_{f}}\left(\phi+\theta \frac{h_{c}}{L W C V \beta_{0} c_{p, w}}\right)
$$

Thus,

$$
L W C_{S}=\frac{\theta_{S} h_{C S}}{V_{S} \beta_{0} c_{B, W}\left(\frac{\theta_{R} h_{c R}}{L W C_{R} V_{R} \beta_{0} c_{D, w}}+\phi_{R}-\phi_{S}\right)}
$$

In equations (7) and (8), $\phi$ is the droplet energy transfer term,

$$
\phi=T_{f}-T-\frac{V^{2}}{2 c_{p, w}}
$$

It was noted above in reference to equation (4) that $\phi_{S}$ and $\phi_{R}$ are equated in this scaling method. Furthermore, the collection efficiency, $\beta_{0}$, must be the same for scale and reference tests. Thus, equation (8) simplifies to

$$
L W C_{S}=L \operatorname{LCC}_{R} \frac{\theta_{S}}{\theta_{R}} \frac{h_{G S}}{h_{C R}} \frac{V_{R}}{V_{S}}
$$

From the Messinger equation, $\theta$ is the air energy transfer term:

$$
\theta=T_{\text {mof }}-T-r \frac{V^{2}}{2 c_{p e}}+.693 \frac{\operatorname{gm~K}}{\text { joule }} \Lambda_{v} \frac{P_{\text {waof }}-P_{v}}{P}
$$

where $r$ is the recovery factor, taken as .875 in this analysis, $p_{w, s w f}$ is the vapor pressure of water at the surface of the model (i.e., at $T_{\text {enof }}$ and $p_{w}$ is the vapor pressure of water in the atmosphere (i.e., at 7 . The vapor pressures for this study were from Pruppacher and $\mathrm{Klett}$.

The scale and reference convective heat transfer coefficients, $h_{c, s}$ and $h_{c, R}$, in equation (10) were evaluated using the following empirical expression from Gelder and Lewis ${ }^{10}$ :

$$
h_{c}=1.244 \frac{k_{e}}{c}\left(\frac{V_{c p_{e}}}{\mu_{e}}\right)^{.4774}
$$

The final scale parameter needed is the spray time, $\tau$. It was found by matching the scale and reference accumulation parameters:

$$
\frac{2 W C_{s} V_{S} \tau_{S}}{P_{l} c_{s}}=\frac{L W C_{R} V_{R} \tau_{R}}{P_{l} c_{R}}
$$

Table III shows results of calculations applying this scaling method to five reference conditions. In reference 2 a number of published scaling methods were shown to wark successfully with rime ice but not for glaze. For this reason, reference conditions were chosen to test this new method with the more-difficult-to-scale glaze ice.

Verification of Constant-Weber-Number Scaling Method. The proposed scaling method was applied in a series of tests in the IRT using the ice-accretion test techniques discussed earlier. Scale sizes of $1 / 2$ and $1 / 3$ the reference cylinder diameters were used.

Due to a transducer calibration error, both reference and scale droplet size, $\delta$ and liquid-water content, $L W C$, were found after the completion of the test to differ from those planned. Table III gives the reference conditions (first line of each test case) which resulted when the test conditions were corrected to give the true droplet size and $L W C$ for the five test cases. The scale conditions listed in Table III then were obtained by applying the constant-We scaling method to these corrected reference conditions. The actual scale conditions tested are given in Table IV. Comparing the scale conditions in Table IV with those in Table III, one can see that the scale airspeeds tested were as much as $8 \%$ lower and scale droplet sizes were up to $18 \%$ lower than the values required by this scaling method. Other scale test conditions were close to those required. The scale Weber numbers tested were lower than the reference values for these tests by as much as $28 \%$.

Figure 9 shows the ice shapes for the conditions of case A in Table IV. The solid line represents the ice shape which resulted from testing at the reference conditions. The dashed line is the scale result. The scale ice shape coordinates have been multiplied by the inverse of the scale factor so that the shapes can be compared directly. The scale test for case A was performed on a $7.6-\mathrm{cm}$ cylinder and resulted in horn-glaze ice very similar in overall shape and quantity of ice to the reference conditions tested on a $15.2-\mathrm{cm}$ 
cylinder. Figures 10 and 11 are also for reference tests with 15.2cm cylinders but with conditions giving different forms of glaze ice. In each case the scale test, using a $7.6-\mathrm{cm}$ cylinder, gave shapes very close to the reference shapes.

Figures 12 and 13 present results for testing with a $7.6-\mathrm{cm}$ reference cylinder and $5.1-\mathrm{cm}$ and $2.5-\mathrm{cm}$ scale cylinders. The results for the $5.1-\mathrm{cm}$ cylinders are shown in dashed lines and the ice shapes for the $2.5-\mathrm{cm}$ cylinders are represented with dotted lines. Figure 12 shows results for horn glaze ice, and figure 13 is for glaze ice at a warmer temperature. In each case, the two scale tests faithfully reproduced the reference ice shape.

Agreement between scale and reference ice shapes was significantly better using the constant-We scaling method than has been demonstrated in past studies using other scaling methods in the $\mathbb{R R T}^{2}$.

\section{Concluding Remarks}

This study has demonstrated the importance of droplet splash to the ice-accretion process. Simple tests performed with $R e$ and We of magnitudes typical of those in icing encounters showed that droplet splash can have a significant effect on surface dynamics. Tests were also performed in the NASA Lewis Icing Research Tumnel which demonstrated that altering the surface tension of the spray cen have a dramatic effect on the ice shape. These observations led to the development of a new scaling method in which the scale and reference $W e$ are the same.

This method was tested in the IRT using cylinders. Because of a transducer calibration error, the scale We was as much as $28 \%$ lower than the reference value. Nevertheless, scale ice shapes closely matched the reference shape when cylinder sizes were scaled by as much as a factor of three. These preliminary results suggest that it may be possible to scale adequately even when We is not held exactly constant. Additional tests are needed to verify this scaling method with a wider range of conditions, with different geometries and with greater size ratios.

Ice-socretion prediction models currently include no consideration of droplet splash. This study demonstrated that consideration of droplet-surface interactions are important to ice accretion and need to be considered not just in scaling methods but in analytical models of ice accretion as well. The Reynolds and Weber numbers need to be investigated carefully to more fully understand their role in the ice-accretion process.

\section{References}

1. Bilanin, A. J., "Proposed Modifications to the Ice Accretion/lcing Scaling Theory," ALAA Paper ALAA-88-0203, January 1988.

2. Anderson, David N.: "Rime-, Mixed- and Glaze-Ice Evaluations of Three Scaling Laws," AIAA 94-0718, January, 1994.
3. Ruff, G.A.: "Analysis and Verification of the Icing Scaling Equations," AEDC-TR-85-30, Vol 1 (Rev), March, 1986.

4. Messinger, B.L., "Equilibrium Temperature of an Unheated Icing Surface as a Function of Airspeed," J. Aeron. Sci. 20 No. 1, Jan. 1953, pp 29-42.

5. Bilanin, A.J. and Teske, ME.: "Numerical Stadies of the Deposition of Material Released From Fixed and Rotary Wing Aircraft," NASA CR-3779, March, 1984.

6. Soeder, Ronald H. and Andracchio, Charles, R, "NASA Lewis Icing Research Tunnel User Manual," NASA TM 102319 , June 1990.

7. Ide, Robert F., "Liquid Water Content and Droplet Size Calibration of the NASA Lewis Icing Research Tumnel," NASA TM 102447, Jan 1990.

8. Pruppacher, Hans R. and Klett, James D., Microphysics of Clouds and Precipitation, Reidel, Boston, 1980.

9. Ingebo, Robert D., "Liquid Fuel Spray Processes in HighPressure Gas Flow," NASA TM86944, July, 1985.

10. Gelder, Thomas F. and Lewis, James P.: "Comparison of Heat Transfer from Airfoil in Natural and Simulated Icing Conditions," NACA TN 2480, September, 1951.

11. Langmuir, Irving and Blodgett, Katharine B.: "A Mathematical Investigation of Water Droplet Trajectories, "Army Air Forces Technical Report No. 5418, February, 1946.

Table I. Order-of-Magnitude Estimates of Nondimensional Parameters Controlling the Dynamics of Impact of a Droplet With a Film

\begin{tabular}{|c|c|c|}
\hline & Rain & Icing \\
\hline$\Delta \delta$ & 0 to $\infty$ & 0 to 10 \\
\hline$\rho_{\omega} U^{2} \delta / \sigma_{w / a}$ & $10^{3}$ & $10^{3}$ to $10^{4}$ \\
\hline$\rho_{\omega} U \delta / \mu_{\omega}$ & $10^{3}$ & $10^{3}$ \\
\hline
\end{tabular}


Table II. Surface Tension of Spray Mixtures

\begin{tabular}{|c|c|c|c|}
\hline \multirow{2}{*}{ Mixture (Concentrations are by Volume) } & \multicolumn{3}{|c|}{$\sigma$, dyne/cm } \\
\hline & 9-2-93 & $12-13-93$ & $12-8-94$ \\
\hline Tap Water $\left(20^{\circ} \mathrm{C}\right)$ & $* *$ & 63.1 & 59.2 \\
\hline IRT Demineralized Water & 48.6 & 65.1 & 59.8 \\
\hline 400:1 IRT Demineralized Water : Liqui-Nox & 28.7 & $* *$ & $*$ \\
\hline 560:1* IRT Demineralized Water : Liqui-Nox & 30.2 & $* *$ & $* *$ \\
\hline 200:1 IRT Demineralized Water : Photo-Flo 200 & 28.4 & 29.8 & $*$ \\
\hline 400:1 IRT Demineralized Water : Photo-Flo 200 & 28.3 & 28.6 & $*$ \\
\hline 600:1 IRT Demineralized Water : Photo-Flo 600 & $* *$ & $*$ & 29.6 \\
\hline
\end{tabular}

Table III. Examples of Scaling With Constant We

\begin{tabular}{|c|l|c|c|c|c|c|c|c|c|c|c|}
\hline Case & Mode & $\begin{array}{c}\text { Diam. } \\
\mathrm{cm}\end{array}$ & $\begin{array}{c}T_{\text {sp }} \\
\mathrm{K}\end{array}$ & $\begin{array}{c}T_{\text {tror }} \\
\mathrm{K}\end{array}$ & $\begin{array}{c}V, \\
\mathrm{~m} / \mathrm{s}\end{array}$ & $\begin{array}{c}\delta, \\
\mu \mathrm{m}\end{array}$ & $\begin{array}{c}L W C, \\
\mathrm{~g} / \mathrm{m}^{3}\end{array}$ & $\begin{array}{c}\tau, \\
\mathrm{min}\end{array}$ & $M$ & $\operatorname{Re} \times 10^{-5}$ & $W e_{\delta} \times 10^{-3}$ \\
\hline \multirow{2}{*}{$\mathrm{A}$} & Ref. & 15.2 & 263.7 & 265.9 & 67.0 & 40.8 & 1.10 & 42.9 & .206 & 7.73 & 2.36 \\
& Scale & 7.6 & 263.3 & 267.2 & 87.6 & 23.9 & 1.30 & 14.0 & .269 & 4.97 & 2.36 \\
\hline \multirow{2}{*}{ B } & Ref. & 15.2 & 266.5 & 268.7 & 67.2 & 40.8 & 1.11 & 42.8 & .205 & 7.62 & 2.39 \\
& Scale & 7.6 & 266.1 & 270.0 & 88.0 & 23.9 & 1.26 & 14.4 & .269 & 4.90 & 2.39 \\
\hline \multirow{2}{*}{ C } & Ref. & 15.2 & 260.9 & 264.9 & 89.5 & 40.7 & .884 & 40.3 & .276 & 10.28 & 4.18 \\
& Scale & 7.6 & 260.2 & 267.1 & 117.4 & 23.7 & .993 & 13.7 & .363 & 6.54 & 4.18 \\
\hline \multirow{3}{*}{ D } & Ref. & 7.6 & 263.7 & 265.9 & 66.7 & 61.0 & .897 & 26.6 & .205 & 3.85 & 3.50 \\
& Scale 1 & 5.1 & 263.5 & 266.6 & 78.1 & 44.6 & .988 & 13.8 & .240 & 2.98 & 3.50 \\
& Scale 2 & 2.5 & 263.0 & 268.2 & 102.3 & 26.0 & 1.12 & 4.6 & .315 & 1.90 & 3.50 \\
\hline \multirow{2}{*}{ E } & Ref. & 7.6 & 266.5 & 268.7 & 67.4 & 58.0 & .887 & 26.7 & .206 & 3.82 & 3.41 \\
& Scale 1 & 5.1 & 266.3 & 269.4 & 78.8 & 42.4 & .963 & 14.0 & .241 & 2.95 & 3.41 \\
& Scaie 2 & 2.5 & 265.8 & 271.1 & 103.3 & 24.7 & 1.05 & 4.9 & .316 & 1.89 & 3.41 \\
\hline
\end{tabular}

Table IV. Scaling Test Conditions

\begin{tabular}{|c|c|c|c|c|c|c|c|c|c|c|c|}
\hline Case & Mode & $\begin{array}{c}\text { Diam., } \\
\text { cm }\end{array}$ & $\begin{array}{c}T_{\text {sto }} \\
\mathrm{K}\end{array}$ & $\begin{array}{c}T_{\text {cos }} \\
\mathbf{K}\end{array}$ & $\begin{array}{l}V, \\
\mathrm{~m} / \mathrm{s}\end{array}$ & $\begin{array}{c}\delta, \\
\mu \mathrm{m}\end{array}$ & $\begin{array}{l}L W C, \\
g / m^{3}\end{array}$ & $\underset{\min }{\tau}$ & $M$ & $\operatorname{Re} \times 10^{-5}$ & $W e_{\delta} \times 10^{-3}$ \\
\hline \multirow{2}{*}{ A } & Ref. & 15.2 & 263.7 & 265.9 & 67.0 & 40.8 & 1.10 & 42.9 & .206 & 7.73 & 2.36 \\
\hline & Scale & 7.6 & 263.7 & 267.2 & 83.9 & 20.7 & 1.24 & 15.4 & .258 & 4.76 & 1.88 \\
\hline \multirow{2}{*}{ B } & Ref. & 15.2 & 266.5 & 268.7 & 67.2 & 40.8 & 1.11 & 42.8 & .205 & 7.62 & 2.39 \\
\hline & Scale & 7.6 & 266.3 & 269.8 & 83.9 & 20.8 & 1.21 & 15.7 & .256 & 4.68 & 1.89 \\
\hline \multirow{2}{*}{ C } & Ref. & 15.2 & 260.9 & 264.9 & 89.5 & 40.7 & .884 & 40.3 & .276 & 10.28 & 4.18 \\
\hline & Scale & 7.6 & 260.4 & 266.6 & 111.8 & 20.7 & .964 & 14.8 & .346 & 6.27 & 3.32 \\
\hline \multirow{3}{*}{ D } & Ref. & 7.6 & 263.7 & 265.9 & 66.7 & 61.0 & .897 & 26.6 & .205 & 3.85 & 3.50 \\
\hline & Scale 1 & 5.1 & 263.4 & 266.3 & 76.7 & 38.5 & .960 & 14.4 & .236 & 2.93 & 2.92 \\
\hline & Scale 2 & 2.5 & 262.9 & 267.5 & 95.6 & 21.3 & 1.08 & 5.1 & .294 & 1.79 & 2.51 \\
\hline \multirow{3}{*}{ E } & Ref. & 7.6 & 266.5 & 268.7 & 67.4 & 58.0 & .887 & 26.7 & .206 & 3.82 & 3.41 \\
\hline & Scale 1 & 5.1 & 266.2 & 269.1 & 76.2 & 46.4 & .967 & 14.4 & .233 & 2.86 & 3.49 \\
\hline & Scale 2 & 2.5 & 265.8 & 270.3 & 95.3 & 21.5 & 1.05 & 5.3 & .292 & 1.76 & 2.52 \\
\hline
\end{tabular}




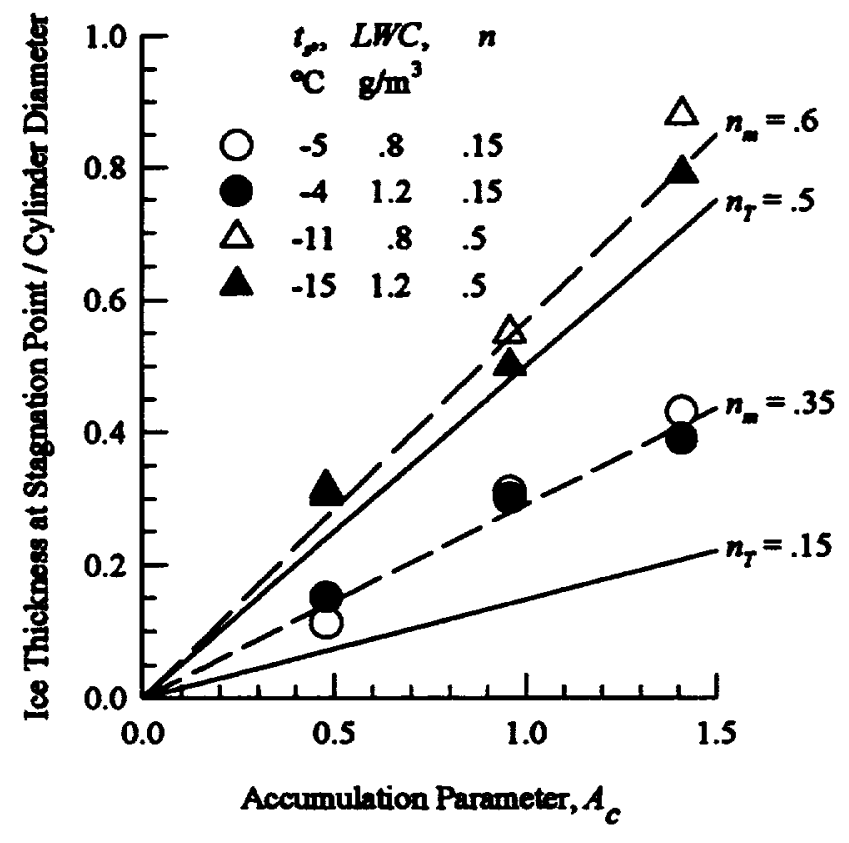

Figure 1. Stagnation Point Ice Accretion on a 2.5-cm-diameter Circular Cylinder. Droplet Velocity, $60 \mathrm{~m} / \mathrm{s}$. (Ref. 1)

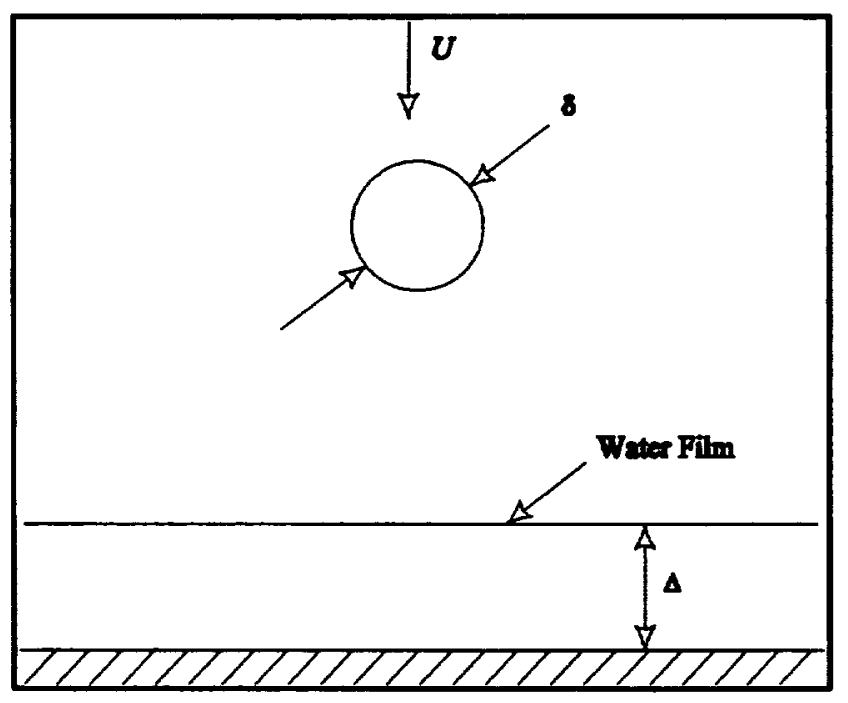

Figure 2. Raindrop Impacting a Shallow Puddle. $\Delta \sim \delta, U$ is much less than the acoustic speed in water.

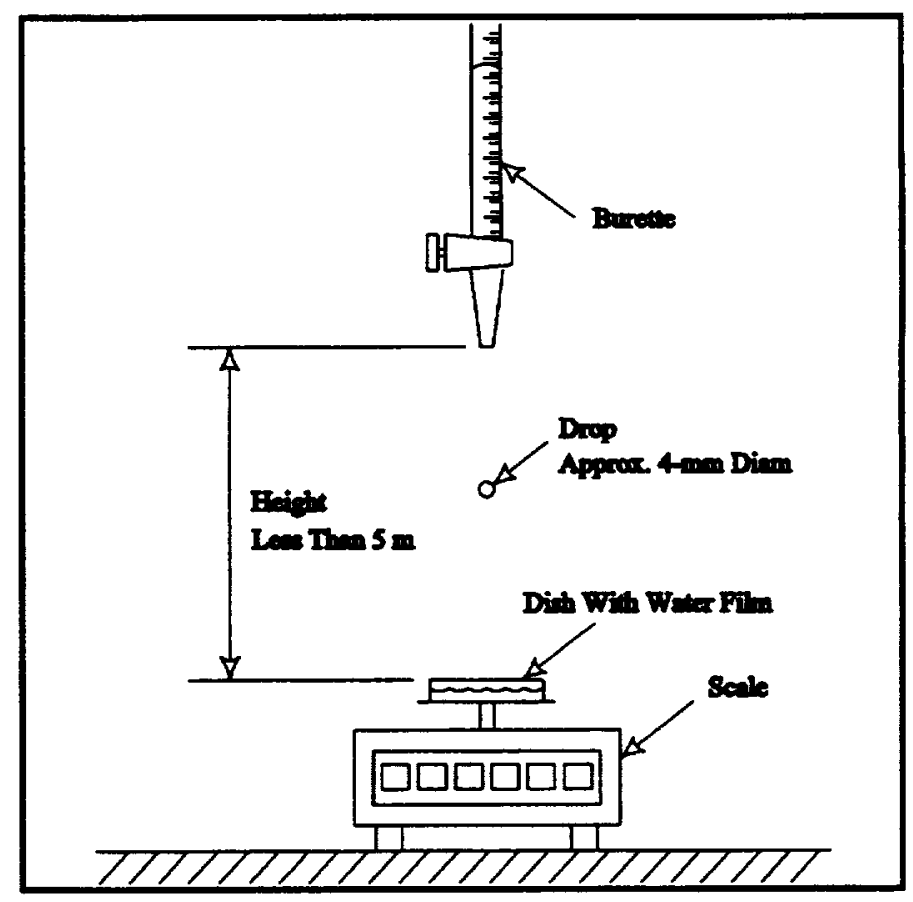

Figure 3. Experimental Setup for Study of Droplet-Film-Impact Dynamics.

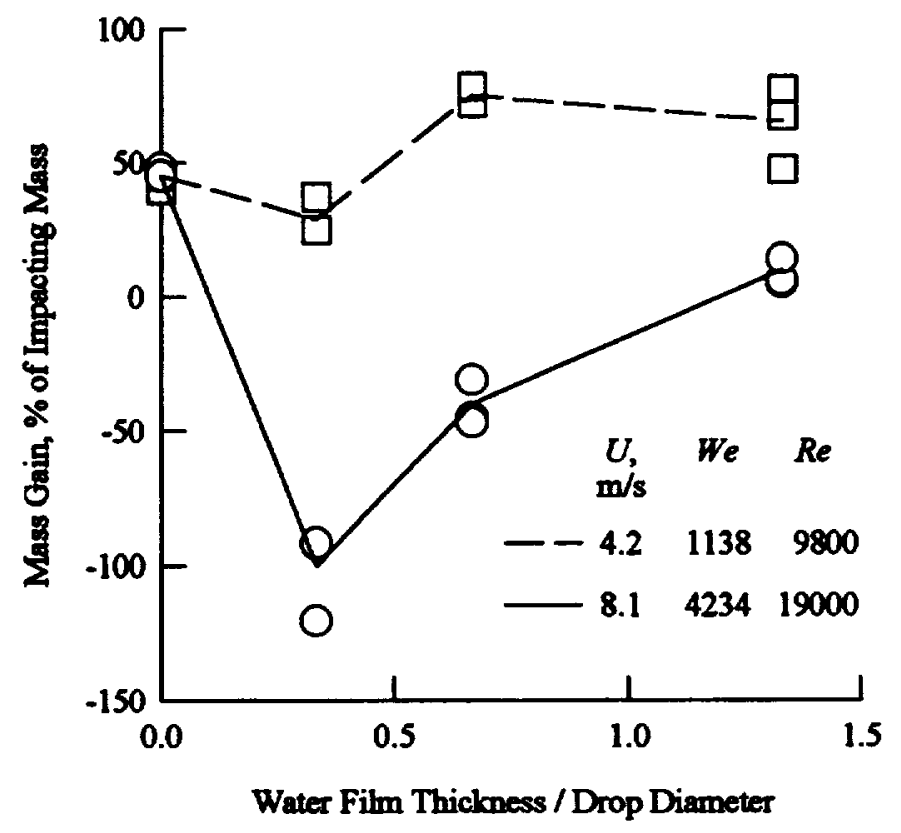

Figure 4. Mass Gain By Water Film Due to Droplet Impact. 


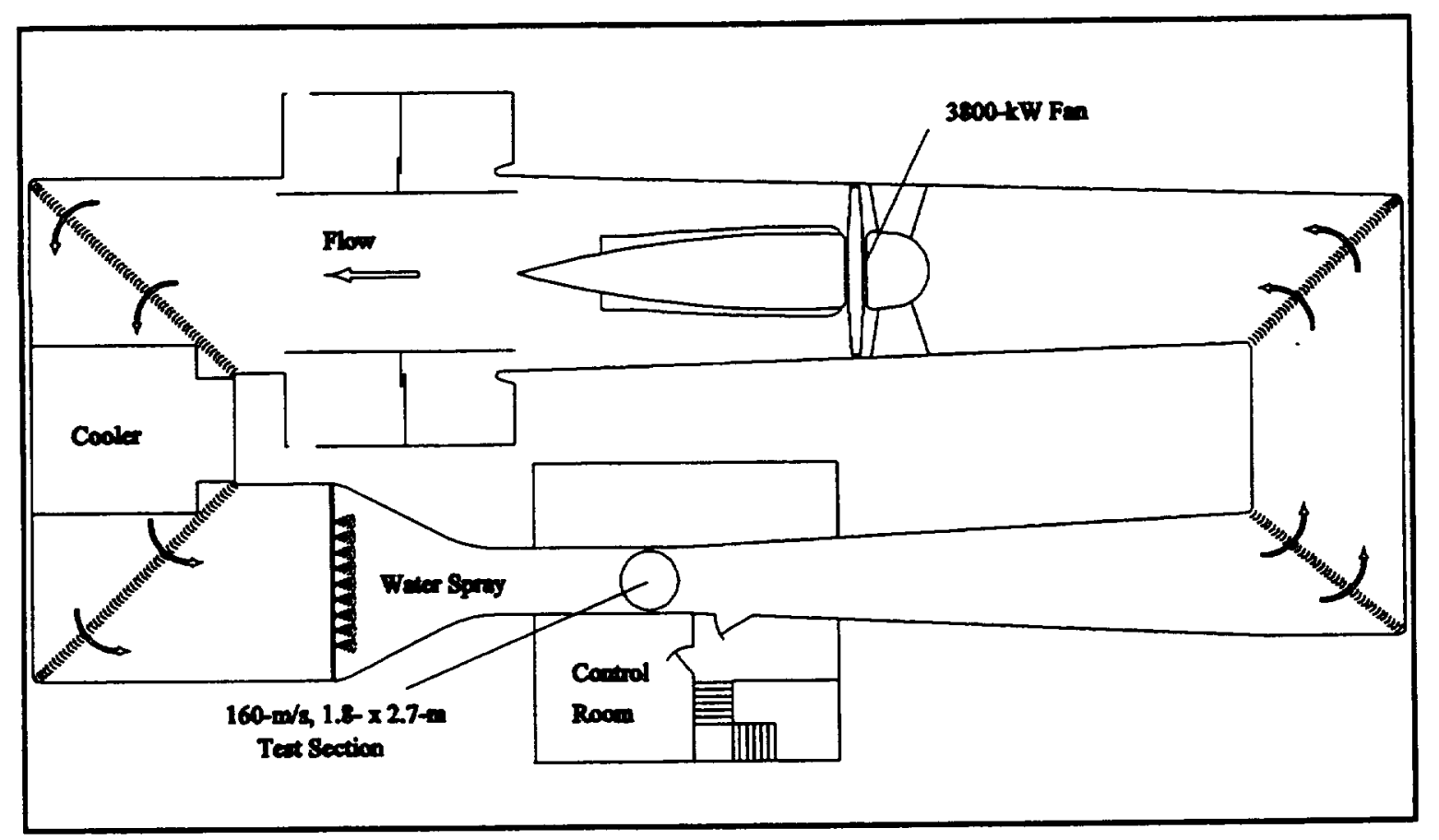

Figure 5. NASA Lewis lcing Research Tunnel (IRT).

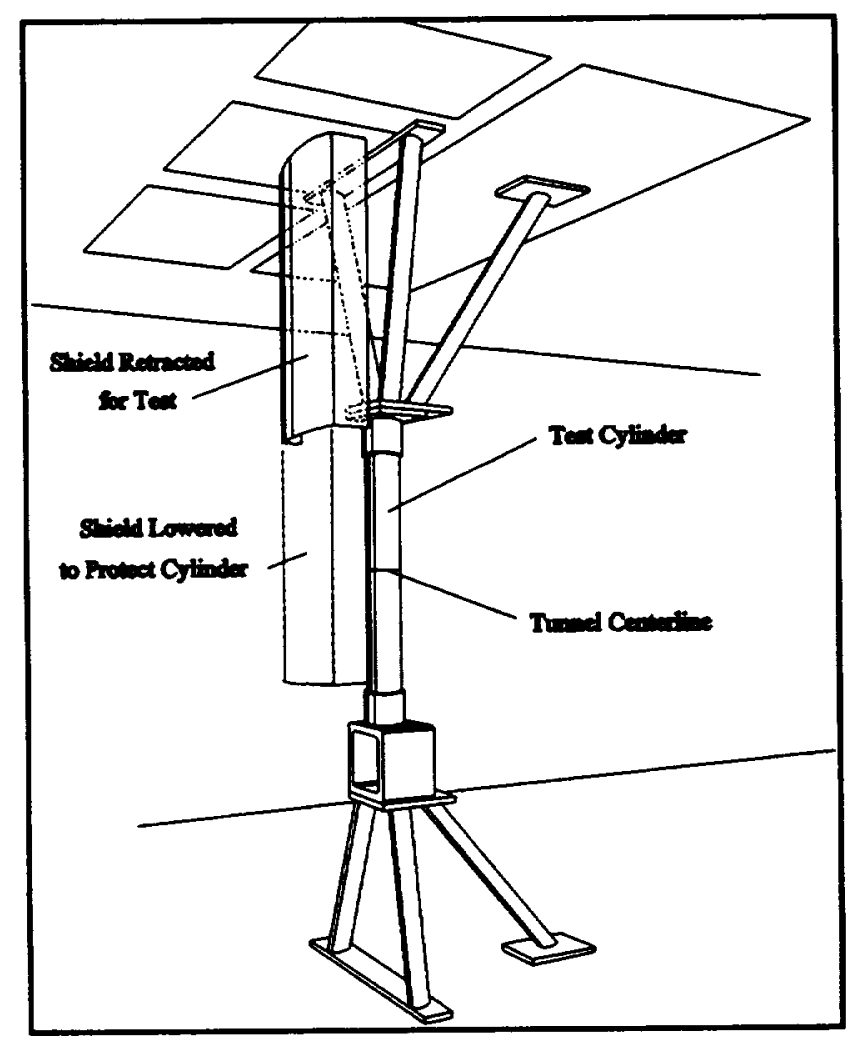

Figure 6. Test Cylinder and Shield Mounted in IRT. 

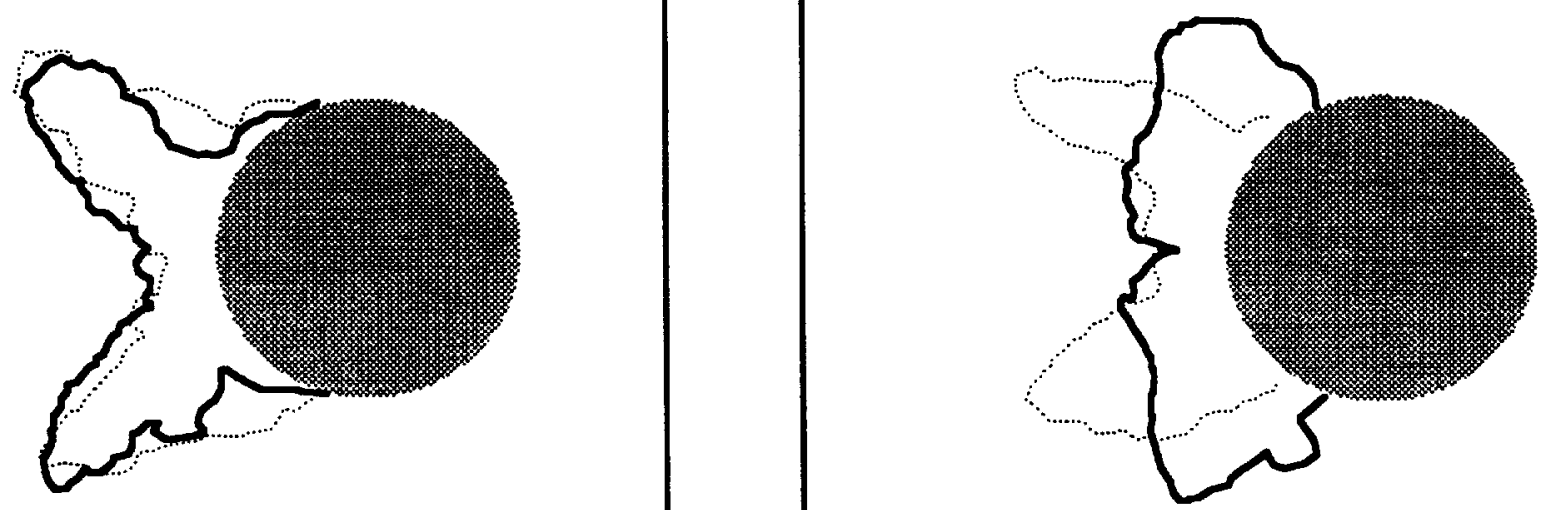

Figure 7. Ice Shape at Model Centerline for Reduced-SurfaceTension Spray. Cylinder diameter, $5 \mathrm{~cm}$; Static Temperature, $266 \mathrm{~K}$; Airspeed, $47 \mathrm{~m} / \mathrm{s}$; Median Volume Droplet Diameter,

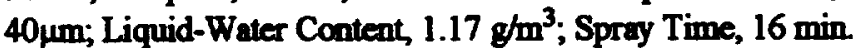
400:1 Water:Liqui-Nox Mixture in Spray Bar System 600:1 Water:Photo-Flo 600 From Single Nozale

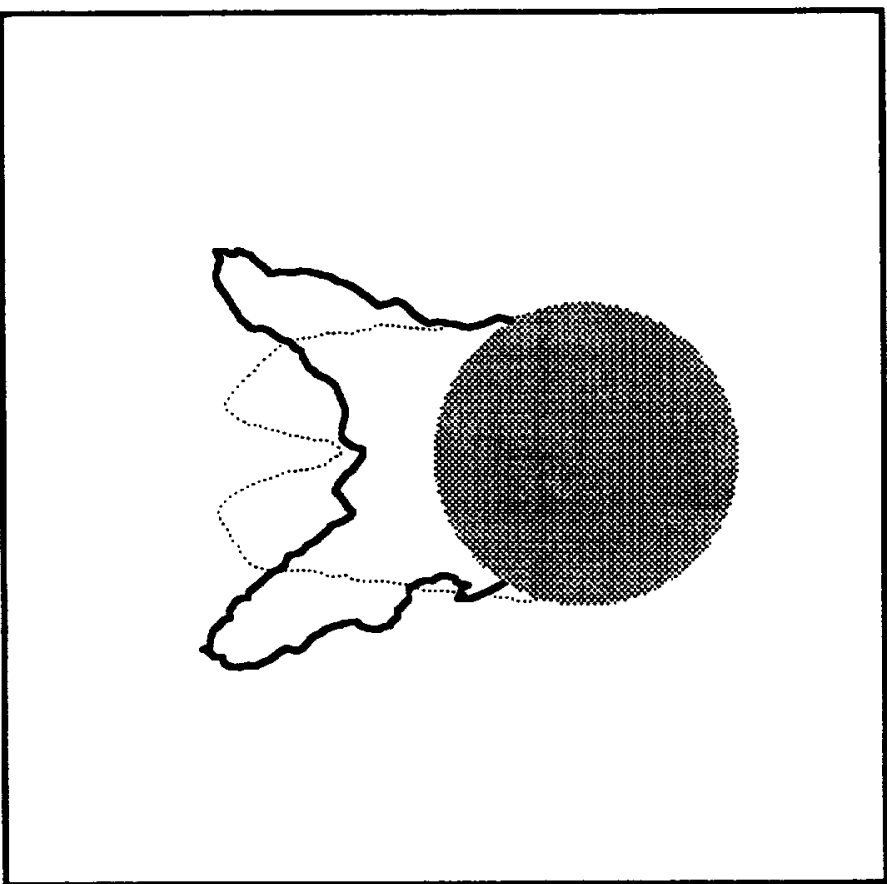

(a) Static Temperature, $261 \mathrm{~K}$; Airspeed, $94 \mathrm{~m} / \mathrm{s}$; Median Volume Droplet Diameter, 30 um; Liquid-Water Content, 1.17 $\mathrm{g} / \mathrm{m}^{3}$; Spray Time, $16 \mathrm{~min}$. Demineralized Water Spray 400:1 Water: Liqui-Nox

(b) Static Temperature, $268 \mathrm{~K}$; Airspeed, $47 \mathrm{~m} / \mathrm{s} ;$ Median

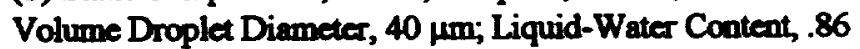
$\mathrm{g} / \mathrm{m}^{3}$; Sprey Time, $18.7 \mathrm{~min}$. Demineralized Water Spray 600:1 Water: Photo-Flo 600From Single Nozzle

Figare \&. (concluded)

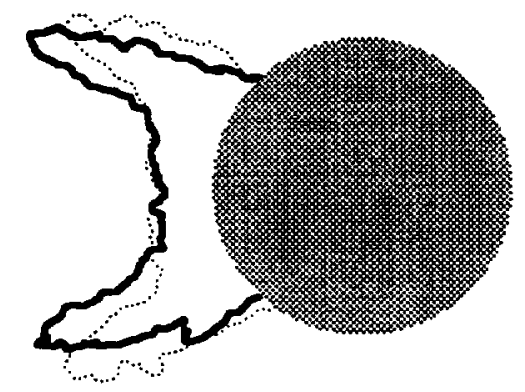

Fizure 9. Scaling with Constant Weber Number: Case A, Table IV.

\section{Reference} Scale 


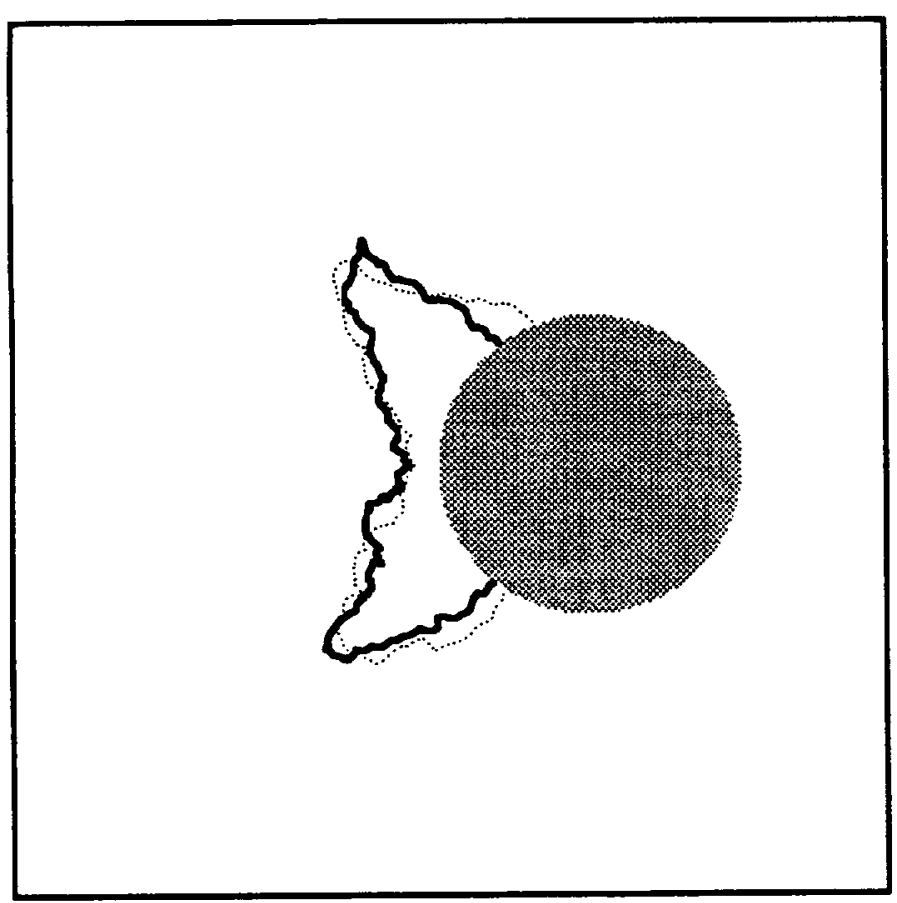

Figure 10. Scaling with Constant Weber Number. Case B in Table IV.

Reference

Scale

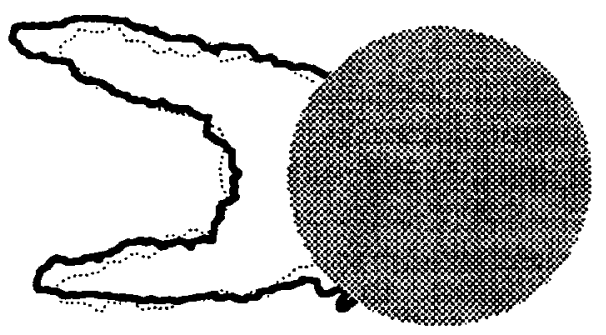

Figure 11. Scaling with Constant Weber Number: Case $C$ in Table IV.

\section{Reference}

Scale

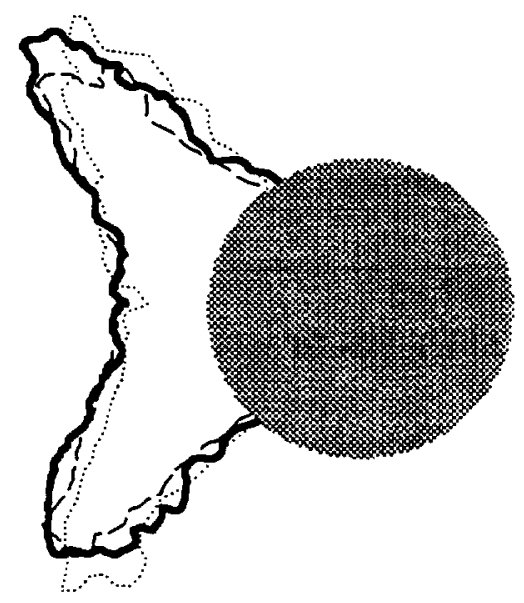

Figure 12. Scaling with Constant Weber Number: Case D in Table IV.
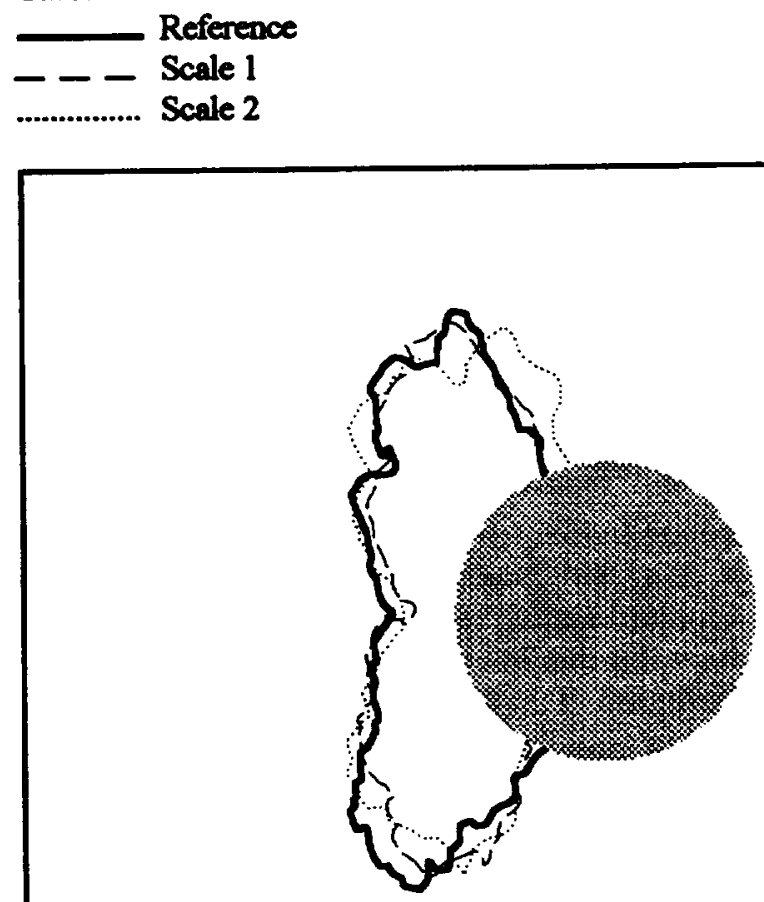

Figure 13. Scaling with Constant Weber Number. Case E in Table IV.

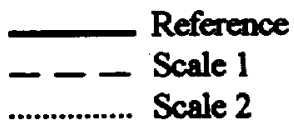




\section{REPORT DOCUMENTATION PAGE}

Public reporting burden for this collection of intormation is estimated to average 1 hour per response, including the time for reviewing instructions, searching existing cala sources, gathening and Davis Highway. Suite 1204, Arlingion. VA 22202-4302, and to the Ottice of Management and Budget, Paperwork Reduction Project (0704-0189). Washington, DC 20503.

\begin{tabular}{|l|l|r|}
\hline 1. AGENCY USE ONLY (Leave blank) & $\begin{array}{r}\text { 2. REPOAT DATE } \\
\text { January } 1995\end{array}$ & $\begin{array}{r}\text { 3. REPORT TYPE AND DATES COVERED } \\
\text { Technical Memorandum }\end{array}$ \\
\hline
\end{tabular}

4. TTTLE AND SUBTTILE

Ice Accretion with Varying Surface Tension

6. AUTHOR(S)

Alan J. Bilanin and David N. Anderson

7. PERFoRMING ORGANIZATION NAME(S) AND ADDRESS(ES)

National Aeronautics and Space Administration

Lewis Research Center

Cleveland, Ohio 44135-3191
5. FUNDING NUMBEAS

WU-505-68-10

8. PERFORMANG ORGANIZATION REPORT NUMBER

E-9375

10. SPONSORINGMONITORINC AGENCY REPORT NUMBER

NASA TM-106826

National Aeronautics and Space Administration

Washington, D.C. 20546-0001

11. SUPPLEMENTARY NOTES

Prepared for the 33rd Aerospace Sciences Meeting and Exhibit sponsored by the American Institute of Aeronautics and Astronautics, Reno, Nevada, January 9-12, 1995. Alan J. Bilanin, Continuum Dynamics, Inc., Princeton, New Jersey, subcontractor to NYMA, Inc. (Subcontract 2705-85, John Deur, Monitor); David N. Anderson, NASA Lewis Research Center. Responsible person, David N. Anderson, organization code 2720, (216) $433-3585$.

12a. DISTRIBUTION/AVAILABILTTY STATEMENT

12b. DISTRIBUTION CODE

Unclassified - Unlimited

Subject Category 03

This publication is available from the NASA Center for Aerospace Information, (301) 621-0390.

13. ABSTRACT (Maximum 200 words)

During an icing encounter of an aircraft in flight, super-cooled water droplets impinging on an airfoil may splash before freezing. This paper reports tests performed to determine if this effect is significant and uses the results to develop an improved scaling method for use in icing test facilities. Simple laboratory tests showed that drops splash on impact at the Reynolds and Weber numbers typical of icing encounters. Further confirmation of droplet splash came from icing tests performed in the NASA Lewis Icing Research Tunnel (IRT) with a surfactant added to the spray water to reduce the surface tension. The resulting ice shapes were significantly different from those formed when no surfactant was added to the water. These results suggested that the droplet Weber number must be kept constant to properly scale icing test conditions. Finally, the paper presents a Weber-number-based scaling method and reports results from scaling tests in the IRT in which model size was reduced up to a factor of 3. Scale and reference ice shapes are shown which confirm the effectiveness of this new scaling method.

14. SUBJECT TERMS

Icing; Scaling; Icing test techniques

15. NUMBER OF PAGES 13

16. PRICE CODE

$\mathrm{A} 03$

\begin{tabular}{|c|c|c|}
\hline $\begin{array}{c}\text { 17. SECURTY CLASSIFICATION } \\
\text { OF REPORT } \\
\text { Unclassified }\end{array}$ & $\begin{array}{c}\text { 18. SECURTY CLASSIFICATION } \\
\text { OF THIS PAGE } \\
\text { Unclassified }\end{array}$ & $\begin{array}{c}\text { 19. SECURITY CLASSIFICATION } \\
\text { OF ABSTRACT } \\
\text { Unclassified }\end{array}$ \\
\hline
\end{tabular}

NSN 7540-01-280-5500

Standard Form 298 (Rev. 2-89) 